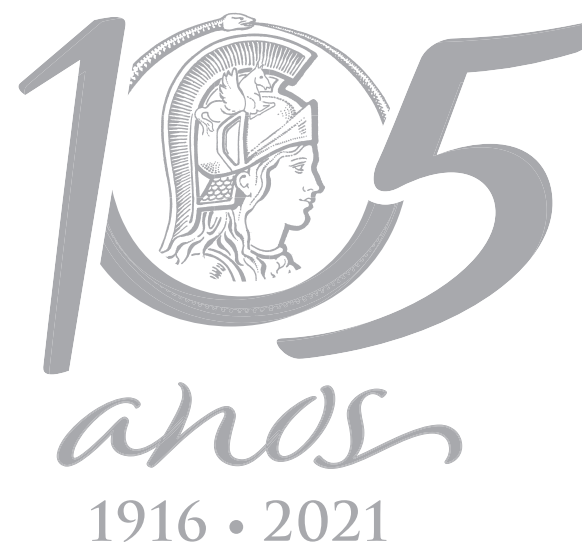

\title{
ECOSYSTEMS
}

\section{On the Dental Formulae of Brazilian Terrestrial Carnivora (Mammalia)}

\author{
FILIPE S. GUDINHO \& MARCELO WEKSLER
}

\begin{abstract}
Key compendia of Neotropical mammals contain conflicting information regarding the dental formulae of Brazilian carnivores. The objective of the present study was to review the dental formulae of Brazilian Canidae, Felidae, Mephitidae, Mustelidae and Procyonidae. We illustrate the dental morphology of all Brazilian genera, and report intra and interspecific tooth variation, and supernumerary teeth. We examined skulls and mandibles of 710 Brazilian terrestrial carnivores, including juvenile and adult specimens. Adults of all genera have three incisors and one canine in each quadrant. Members of the canid family have the following postcanine formula $P 4 / 4$ and $M 2 / 3$, except Speothos venaticus (M 1/2); felids have $P 3 / 2$ and $M 1 / 1$; mephitids present $P 2 / 3$ and $M$ 1/2; mustelids show $P$ 2-4/2-3 and $M 1 / 2$; and finally, procyonids have $P 4 / 4$ and $M$ $2 / 2$, except Potos flavus (P $3 / 3$ ). Supernumerary teeth were found in individuals of seven genera in every family except Procyonidae. Although our results corroborate previous descriptions based on vouchered material, we detected several incongruences being replicated, possibly due to the lack of examination of museum vouchers, propagating erroneous information without critical analysis. Finally, we present a dichotomous key based on the review of dental morphology.
\end{abstract}

Key words: Canines, carnassial tooth, incisors, molars and premolars.

\section{INTRODUCTION}

Teeth play a crucial role in mammalian evolution (Bergqvist 2003, Hillson 2005, Ungar 2010) and are important for the classification, diagnosis, and identification of mammalian taxa, in particular carnivores (e. g.: Cope 1879, Savage 1976, Van Valkenburgh 1991). In fact, the order Carnivora is defined, among other characters, by the loss of the third upper molar (Wesley-Hunt \& Flynn 2005) and by the presence of enlarged shearing postcanines, the carnassials, considered a key diagnostic trait for the order (Ungar 2010). Likewise, the loss of the third lower molar is a diagnostic character for the suborder Feliformia (Wesley-Hunt \& Flynn 2005). Members of the order typically have three small incisors, one large canine, and a variable number of pointed premolars and molars with high cusps (Hillson 2005, Ungar 2010).

Researchers have investigated the dentition of Neotropical Carnivora since the early studies of New World mammal fauna (Winge 1895, PaulaCouto 1950, 1979). Currently, several books about Neotropical and Brazilian mammals describe the dental formulae of Carnivora species and are used as primary source for research (e.g.: Reis et al. 2010, Eisenberg 1989, Emmons \& Feer 1997, Eisenberg \& Redford 1999). While performing a revision of this information in the literature, we detected several inconsistencies among these sources as well as factual errors for a few of the taxa in these publications. 
The aim of this contribution is, therefore, to presenta description of the dental loci of Brazilian terrestrial carnivores, based on the examination of an extensive series of vouchered specimens. We report the dental formulae for all genera of Brazilian carnivores, document cases of intra and interspecific variation and supernumerary tooth, and present the replacement order of deciduous teeth in several taxa. We illustrate the general dental morphology of all genera, and provide discussion about tooth identity and general trends as well as a dichotomous key based on dental morphology.

\section{MATERIALS AND METHODS}

We analyzed 710 specimens housed at the mammal collection of the Museu Nacional/ UFRJ, Rio de Janeiro, Brazil. We examined only specimens with both skull and mandible: in the case of specimens with missing teeth, the alveoli were used to determine the total number of teeth (Novacek 1986). We included all terrestrial carnivore genera with families represented in Brazil, namely Felidae, Canidae, Mephitidae, Mustelidae, and Procyonidae. We examined all Brazilian species within these genera and defined as juvenile those individuals with deciduous teeth present, and adults as those individuals with full permanent dentition. Taxonomic nomenclature follows Paglia et al. (2012); see Table I for included taxa and sample size, and appendix 1 for a list of all examined specimens.

Dental nomenclature follows Owen (184045) and Luckett (1993). These authors defined incisors as those teeth which are placed at the pre-maxillary bone and the corresponding occluding teeth of the lower jaw; the canines as the first tooth on the maxillary bone and its counterpart at the lower jaw, which occlude in front of the upper canine; the premolars are the remaining teeth which are replaced; while the molars are those postcanine that are not replaced. The dental formula is presented in quadrants as traditionally depicted in mammalogy textbooks: I $\mathrm{x} / \mathrm{x}, \mathrm{C} \mathrm{x} / \mathrm{x}, \mathrm{P} \mathrm{x} / \mathrm{x}, \mathrm{M}$ $x / x$, followed by the total number of teeth. The abbreviation "I" means incisors, " $C$ " canines, " $P$ " premolars, and " $\mathrm{M}$ " molars. Letters in uppercase refer to upper teeth, while in lowercase to lower teeth. The dental descriptions presented were based on adult specimens, unless noted otherwise.

\section{RESULTS}

Five genera of Canidae, three of Felidae, four of Mustelidae, one of Mephitidae, and five of Procyonidae have species occurring in Brazil (Table I). All examined specimens have on each quadrant three incisors, located on the premaxilla, and one canine, the first tooth on the maxilla. However, the number of premolars and molars vary, and are presented below separately by family.

\section{Canidae}

All examined members of the family Canidae, except Speothos venaticus (Lund 1842), display the dental formula 1 3/3, C 1/1, P 4/4, M 2/3= 42 and the same general dentition pattern (Fig. 1a). Upper premolars increase in size posteriorly, and the carnassial (P4) is the largest tooth with the highest cusps. The two molars are enlarged buccolingually and have complex crowns composed of four main cusps, and crests arranged in two parallel lines; M2 is smaller than M1. In the lower toothrow, premolars also increase and molars decrease in size posteriorly. The first molar is always the largest postcanine tooth, with carnassial blades positioned mesially 
Table I. List of Carnivora taxa examined, with sample size and dental formula. Taxa marked with an asterisk (*) denote intraspecific variation in dental formula.

\begin{tabular}{|c|c|c|c|}
\hline Family & Species & Sample size & Dental formula \\
\hline \multirow{7}{*}{ Canidae } & Atelocynus microtis & 1 & \multirow{5}{*}{$13 / 3, C 1 / 1, P$ 4/4, M 2/3 } \\
\hline & Cerdocyon thous* & 153 & \\
\hline & Chrysocyon brachyurus & 25 & \\
\hline & Lycalopex gymnocercus & 1 & \\
\hline & Lycalopex vetulus & 20 & \\
\hline & Lycalopex sp. & 1 & $13 / 3, C 1 / 1, P 4 / 4, M 3 / 3$ \\
\hline & Speothos venaticus* & 5 & I 3/3, C 1/1, P 4/4, M 1/2 \\
\hline \multirow{7}{*}{ Felidae } & Leopardus braccatus* & 3 & I 3/3, C 1/1, P 2-3/2, M 1/1 \\
\hline & Leopardus pardalis* & 36 & \multirow{6}{*}{ I 3/3, C 1/1, P 3/2, M 1/1 } \\
\hline & Leopardus tigrinus* & 28 & \\
\hline & Leopardus weidii & 12 & \\
\hline & Panthera onca* & 26 & \\
\hline & Puma concolor & 22 & \\
\hline & Puma yagouaroundi & 20 & \\
\hline \multirow{2}{*}{ Mephitidae } & Conepatus semistriatus* & 6 & \multirow{2}{*}{ I 3/3, C 1/1, P 2/3, M 1/2 } \\
\hline & Conepatus chinga & 1 & \\
\hline \multirow{6}{*}{ Mustelidae } & Eira barbara & 33 & \multirow{3}{*}{$13 / 3$, C 1/1, P 3/3, M 1/2 } \\
\hline & Galictis vittata* & 5 & \\
\hline & Galictis cuja & 43 & \\
\hline & Lontra longicaudis* & 14 & \multirow{2}{*}{$13 / 3, C 1 / 1, P 4 / 3, M 1 / 2$} \\
\hline & Pteronura brasiliensis & 8 & \\
\hline & Mustela africana* & 4 & I 3/3, C 1/1, P 2-3/2, M 1/2 \\
\hline \multirow{4}{*}{ Procyonidae } & Bassaricyon alleni & 3 & \multirow{3}{*}{$13 / 3, \mathrm{C} 1 / 1, \mathrm{P} 4 / 4, \mathrm{M} 2 / 2$} \\
\hline & Nasua nasua & 138 & \\
\hline & Procyon cancrivorus & 43 & \\
\hline & Potos flavus & 59 & $13 / 3, C 1 / 1 /$, P 3/3, M 2/2 \\
\hline
\end{tabular}

on the trigonid, and three low cusps distally on the talonid.

Speothos venaticus (Fig. 1b) is the only Brazilian canid with just one upper and two lower molars, i.e., I 3/3, C 1/1, P 4/4, M 1/2 = 38 . S. venaticus also shows simplification on $\mathrm{m} 1$ (lower carnassial) by both losing the metaconid and having a single-cuspidate talonid, while the $\mathrm{m} 1$ of other canids have five cusps. Finally, the second lower molar of S. venaticus has a single cusp. Nevertheless, one specimen of $S$. venaticus (MN75089), representing 20\% of the examined individuals, has two upper molars in both sides of the jaw instead of one (Fig. 2a). This additional molar is extremely small, peglike, and without distinguishable cusps. 


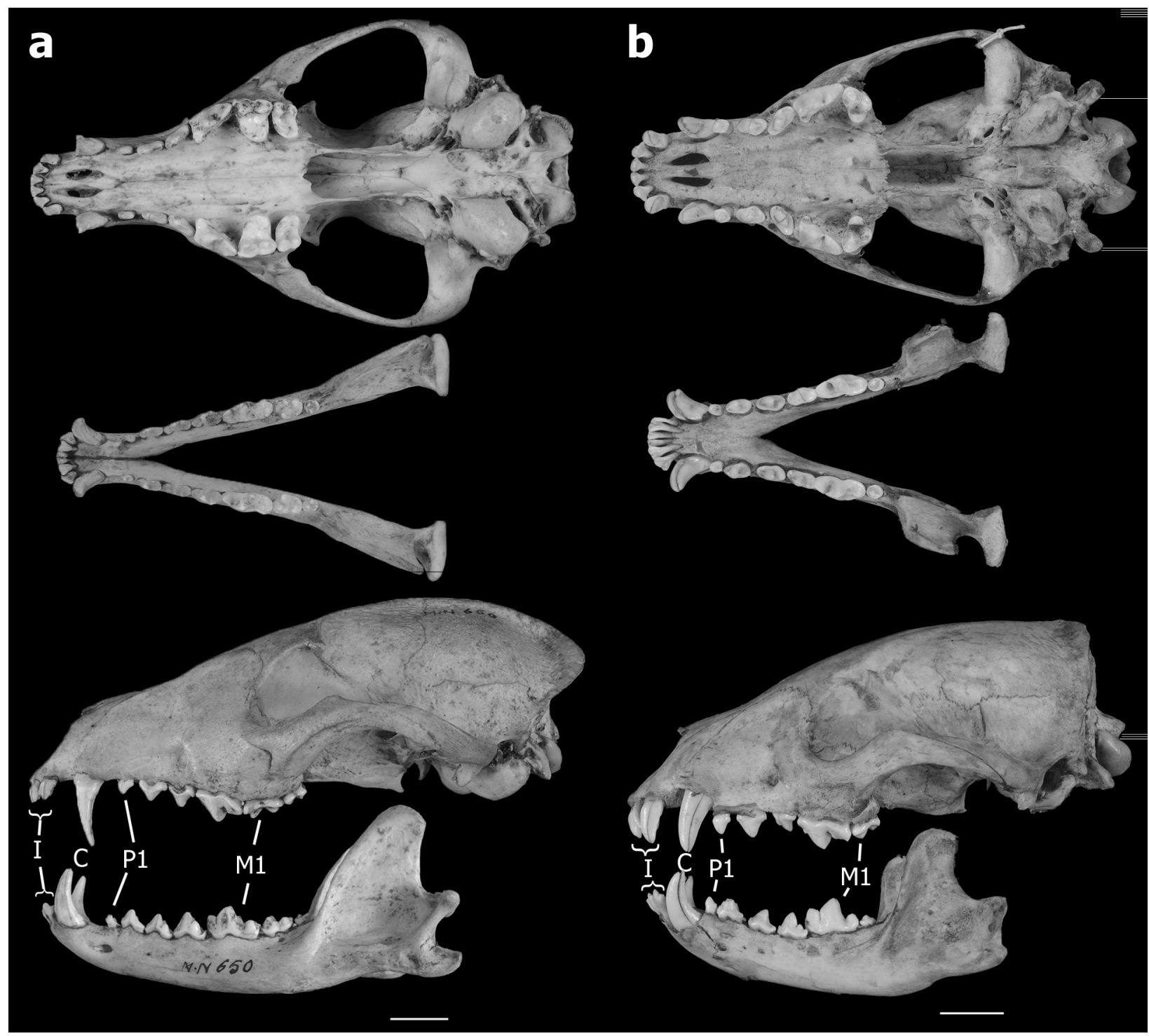

Figure 1. Occlusal (top) and lateral (bottom) views of the skull and mandible of: a) Atelocynus microtis (MN650); b) Speothos venaticus (MN25670). Abbreviation "I" means incisors, "C" canines, "P" premolars and "M" molars. Scale bar $=2 \mathrm{~cm}$.

Specimens of Cerdocyon thous (Linnaeus 1766) and Lycalopexspp. also have supernumerary teeth. In one C. thous specimen (MN79593), one extra tooth, probably a premolar, is found positioned lingually to the left upper fourth premolar (Fig. 2b), and its shape and position resemble a common carnassial. Two specimens have a third upper molar, one of them (MN25683) possessing a $\mathrm{M} 3$ alveolus (but no tooth) distally to the right M2, while the other (MN71092) had a pair of M3's of equal size (Fig. 2C). On the lower jaw, three specimens (MN79393, MN79509, MN81791) have a tiny right fourth molar (Fig. 2d), and one specimen (MN25601) showed an alveolus distal to the left $\mathrm{m} 3$. A single specimen of $C$. thous (MN25579), representing $0.65 \%$ of our sample, did not have the $\mathrm{m} 3$, showing $13 / 3, \mathrm{C} 1 / 1$, P 4/4, M 2/2. Finally, one unidentified specimen of Lycalopex (MN652) showed an extra pair of upper molars (M3). 


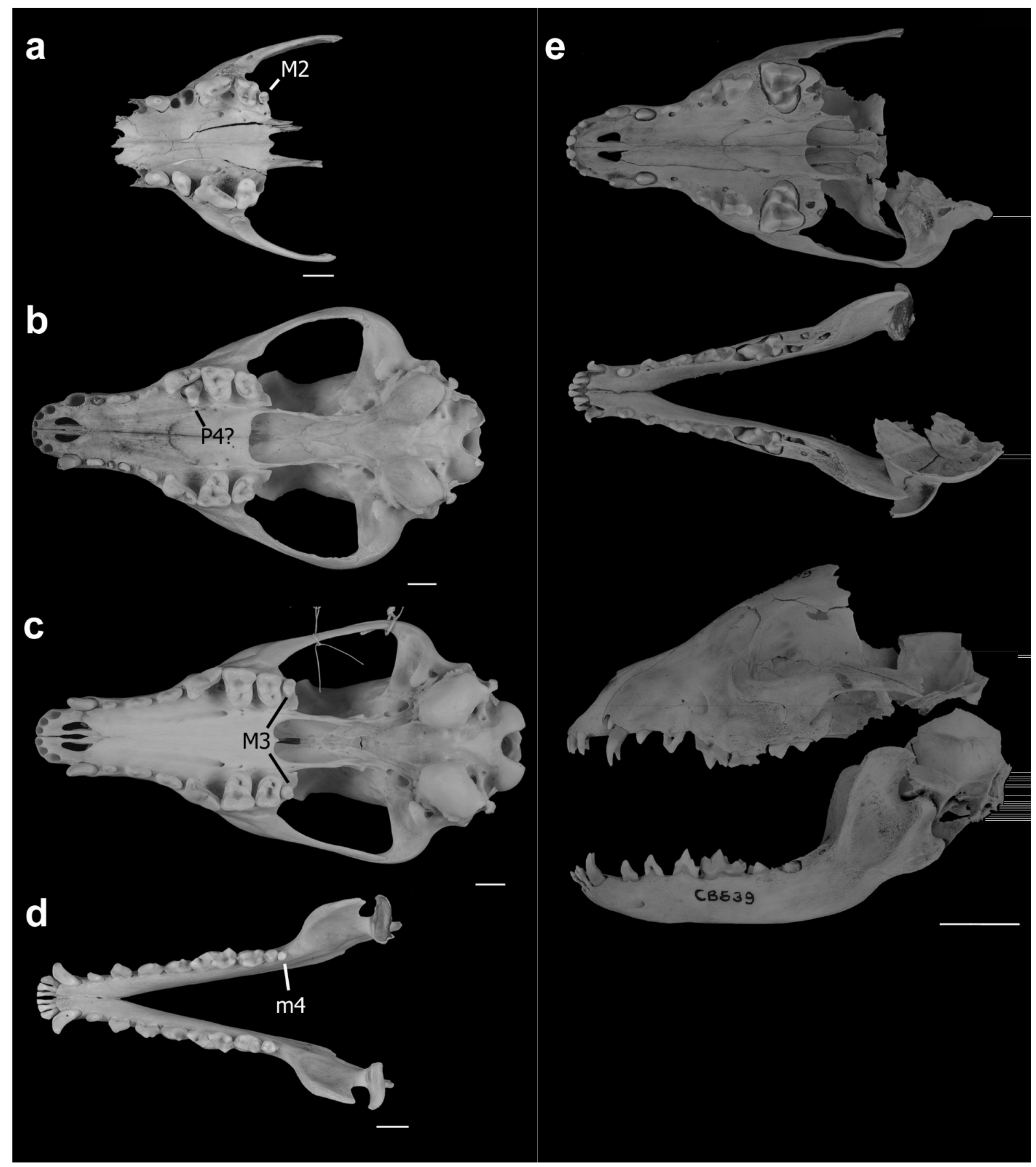

Figure 2. Canidae dentitions. a) Ventral view of a partial skull of Speothos venaticus (MN75089) with two upper molars instead of one; b) Ventral view of a Cerdocyon thous skull (MN79593) with an extra premolar positioned lingually to left carnassial; c) Ventral view of a C. thous skull (MN71092) with three upper molars instead of two; d) Mandible of $C$. thous (MN79393) in occlusal view with four lower molars on the right side and three on the left side; e) Occlusal (top) and lateral (bottom) views of a juvenile C. thous exemplar (MN81779) showing small pits positioned lingually to incisors, canines and premolars, through where permanent teeth would have erupted and replaced the deciduous ones. Note that P1 and P2, P3, P4 have unsynchronized eruptions, and dP3 and dP4 resemble a carnassial and a molar, respectively. Abbreviation "P" means premolars and " $M$ " molars. Scale bar $=2 \mathrm{~cm}$. 


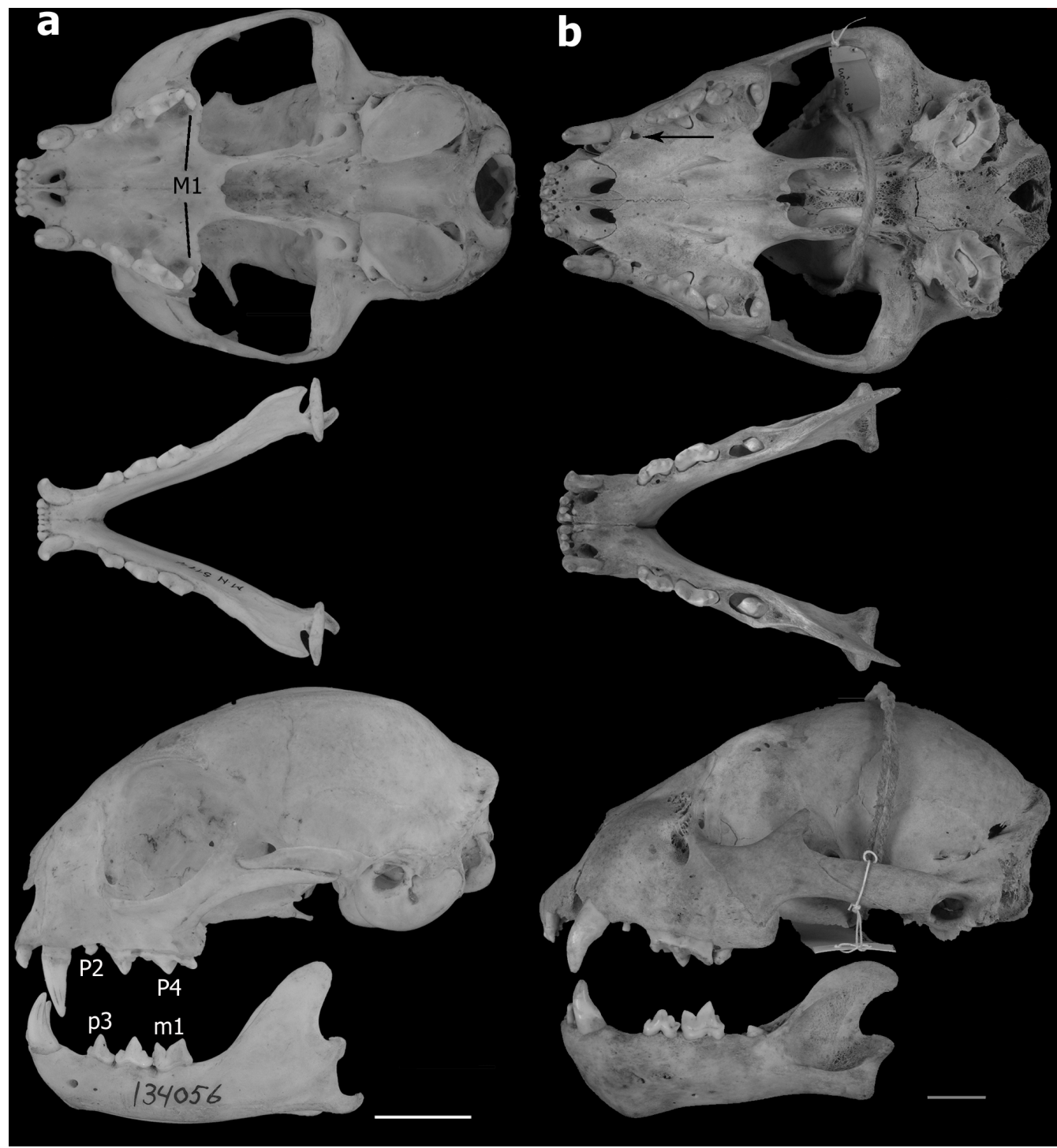

Figure 3. Occlusal (top) and lateral (bottom) views of the skull and mandible of: a) Leopardus wiedii (MN5114); b) Panthera onca (MN32376). Note the small pits positioned lingually to the incisors, canines and premolars (arrow) on both upper and lower jaws, through where the permanent dentition would have erupted. The third and fourth deciduous premolars resemble the shape of permanent fourth premolar and first molar, respectively. Abbreviation " $\mathrm{P}$ " means premolars and " $\mathrm{M}$ " molars. Scale bar $=2 \mathrm{~cm}$.

Eleven juvenile specimens of $C$. thous (Fig. 2e) were employed to assess shedding and replacement patterns among canids (appendix 1). We could not find any evidence of shedding of the first postcanine tooth even among the youngest exemplars, although we found replacement evidence of all other premolars. The second deciduous premolar possesses the same general shape of the permanent one, while the third deciduous premolar has a carnassial shape, and the fourth one has a molar shape. Unfortunately, no juvenile specimen of $S$. venaticus was available for description.

\section{Felidae}

Brazilian cats usually have the traditional felid permanent dental formula I 3/3, C 1/1, P 3/2, M $1 / 1=30$ (Fig. 3a). On the upper jaw, the three premolar teeth increase in size posteriorly. A conspicuous carnassial is the largest premolar in adult specimens, although the predecessor tooth has a cusp with almost the same height. A single reduced molar, simple in form and without conspicuous cusps, is hidden by the carnassial in lateral view. On the lower jaw, the three postcanine teeth have the same height, but the first two, the premolars, have just one 


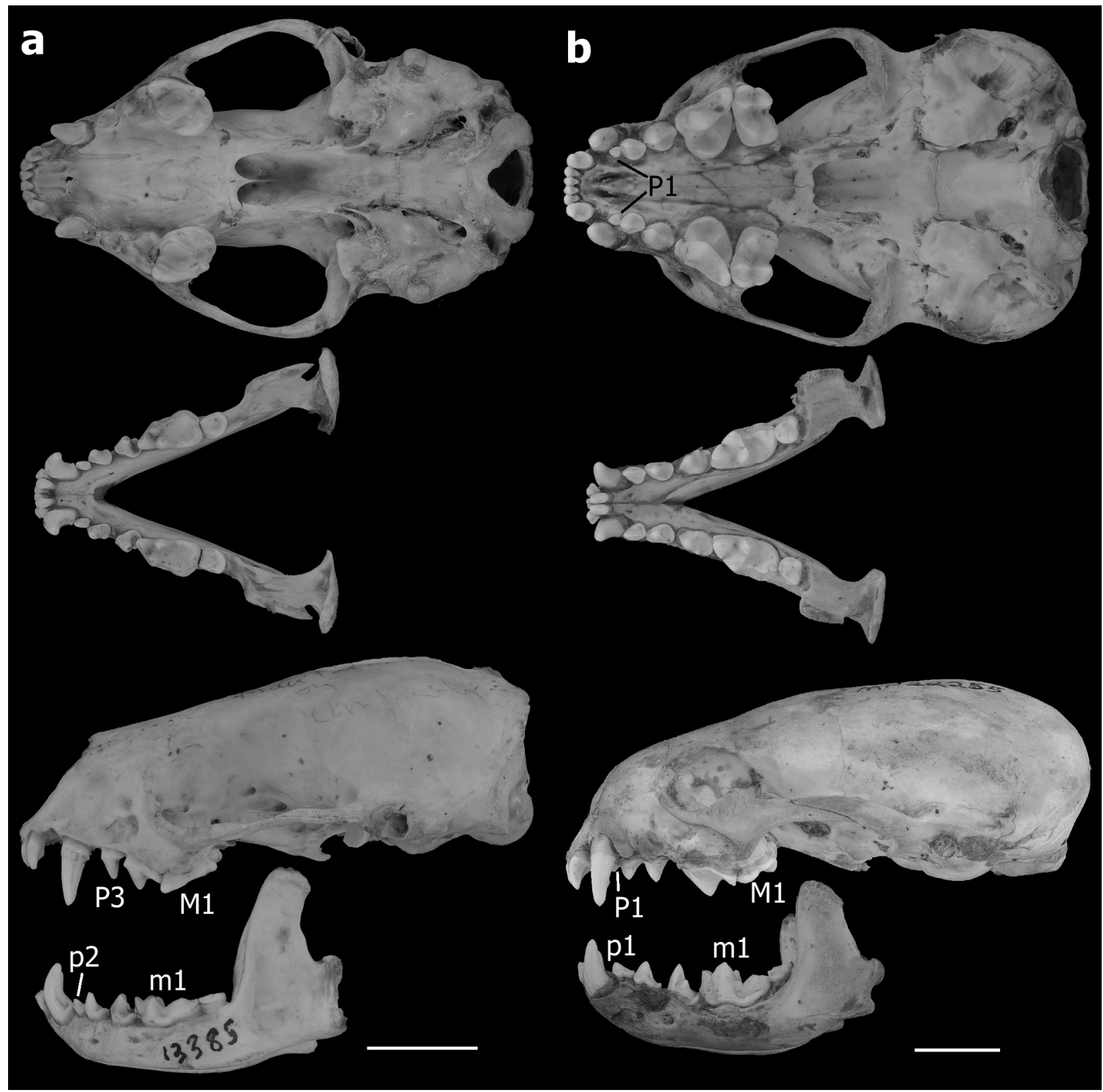

Figure 4. Occlusal (top) and lateral (bottom) views of the skull and mandible of: a) Conepatus semistriatus (MN13385); b) Lontra longicaudis (MN22255). Abbreviation " $\mathrm{P}$ " means premolars and "M" molars. Scale bar $=2 \mathrm{~cm}$.

higher cusp each, while the molar has two cusps and crests, typical of a carnassial. This molar lacks a conspicuous talonid.

Individuals of several species depart from this pattern. Of the three examined specimens of Leopardus braccatus (Cope 1889), two (MN4868, MN24904) have just two upper premolars, and one specimen (MN63629) has three upper premolars on one side and two on the other side. Four specimens (MN3133, MN49354, MN79565, MN84552) of L. tigrinus (Schreber 1775) also have just two upper premolars, representing approximately $14 \%$ of all examined specimens. Finally, one specimen (MN5679) of L. pardalis (Linnaeus 1758) has three premolars on the lower jaw, and one (MN48869) of Panthera onca 


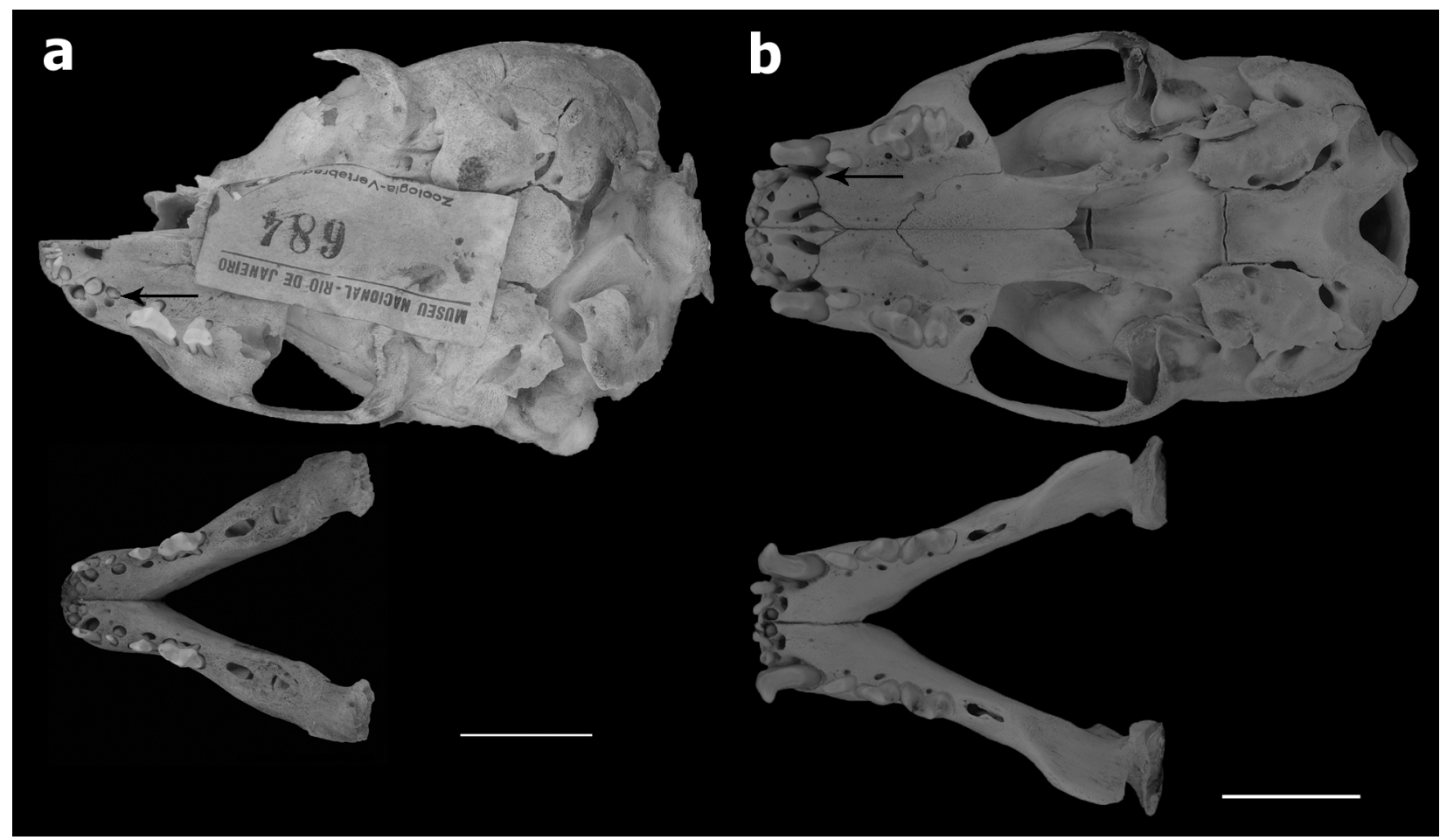

Figure 5. Occlusal view of the skull and mandible of juvenile specimens of a) Lontra longicaudis (MN684); b) Eira barbara (MN74385). Note the pits close to the base of each tooth (arrows), indicating replacement, except in P1 of $L$. longicaudis. Also note the carnassial and molar shapes of third and fourth premolars. The molar is about to erupt in these individuals. Scale bar $=2 \mathrm{~cm}$.

(Linnaeus 1758) has three premolars on one hemimandible.

Four juvenile specimens of $P$. onca (Fig. 3b; appendix 1) have a series of perforations close to the base of incisors, canine, and premolars, indicating shedding. The carnassial shape of the third upper deciduous postcanine and the molar shape and size of the fourth upper deciduous postcanine reinforce that these teeth are the last premolars. These perforations are also found close to the lower teeth.

\section{Mephitidae}

Conepatus is the single genus of the family Mephitidae that occurs in Brazil; its members have a typical dental formula of $13 / 3$, C $1 / 1$, $\mathrm{P} 2 / 3, \mathrm{M} 1 / 2=32$ (Fig. 4a), but one specimen (MN30000) of C. semistriatus (Boddaert 1785), among a total of six, has three upper premolars.
Postcanines increase in size posteriorly, with the first premolar tooth with only one cusp and the last premolar with two cusps forming the traditional carnassial blade. The last tooth, the molar, is the largest one.

On the lower jaw, premolars increase in size posteriorly, and the three premolars have a single cusp each. Molars decrease in size posteriorly, and the lower carnassial (m1) is the largest mandibular teeth, with its talonid larger than its trigonid. The m1's talonid of Conepatus specimens was the largest among all examined Carnivora. The second molar is more squared, without conspicuous cusps.

The total sample size of $C$. chinga (Molina 1782) and C. semistriatus consisted of seven individuals, and no juvenile specimen with deciduous teeth was available for examination. 


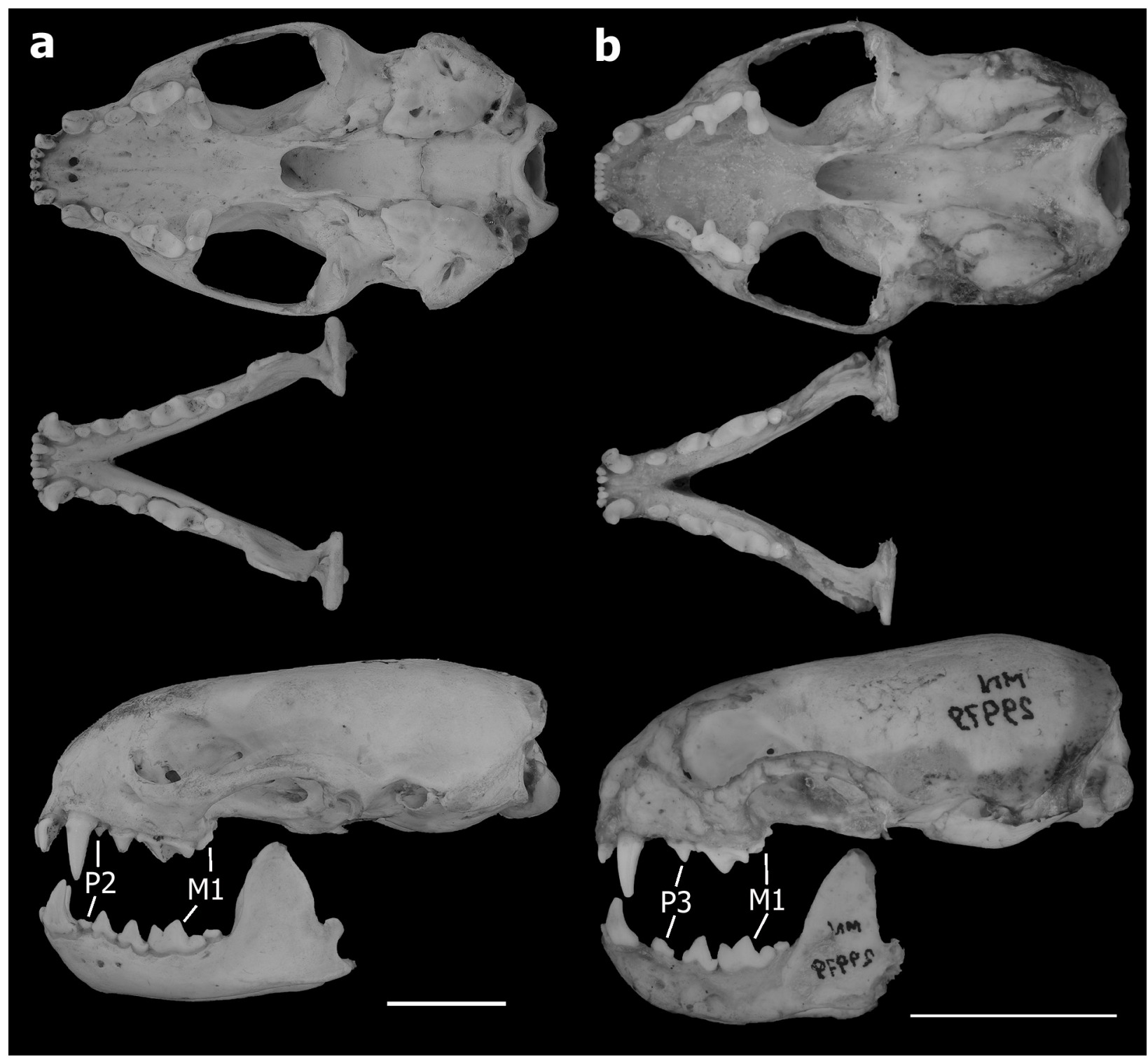

Figure 6. Occlusal (top) and lateral (bottom) views of the skull and mandible of a) Galictis cuja (MN29998); b) Mustela africana (MN29979). The lateral view of M. africana skull was mirrored horizontally to facilitate understanding. Abbreviation " $\mathrm{P}$ " means premolars and " $\mathrm{M}$ " molars. Scale bar $=2 \mathrm{~cm}$.

An enlarged series is needed to ascertain the variation in this genus.

\section{Mustelidae}

The permanent dental formula of mustelids is the most variable among Brazilian terrestrial carnivores. Every mustelid has three incisors, one canine, and one upper and two lower molars, but the number of premolars varies. specimens of Pteronura brasiliensis (Gmelin
1788) and Lontra longicaudis (Olfers 1818) have I 3/3, C 1/1, P 4/3, M 1/2 = 36 (Fig. 4b). The premolars increase posteriorly in size, and are very close to each other. The first premolar is positioned lingually to the canine, being almost hidden by the latter in lateral view. The last upper premolar, the carnassial, is a very large tooth, larger than the single upper molar. On the lower jaw, one incisor is positioned behind the other two in each quadrant. The three premolars 


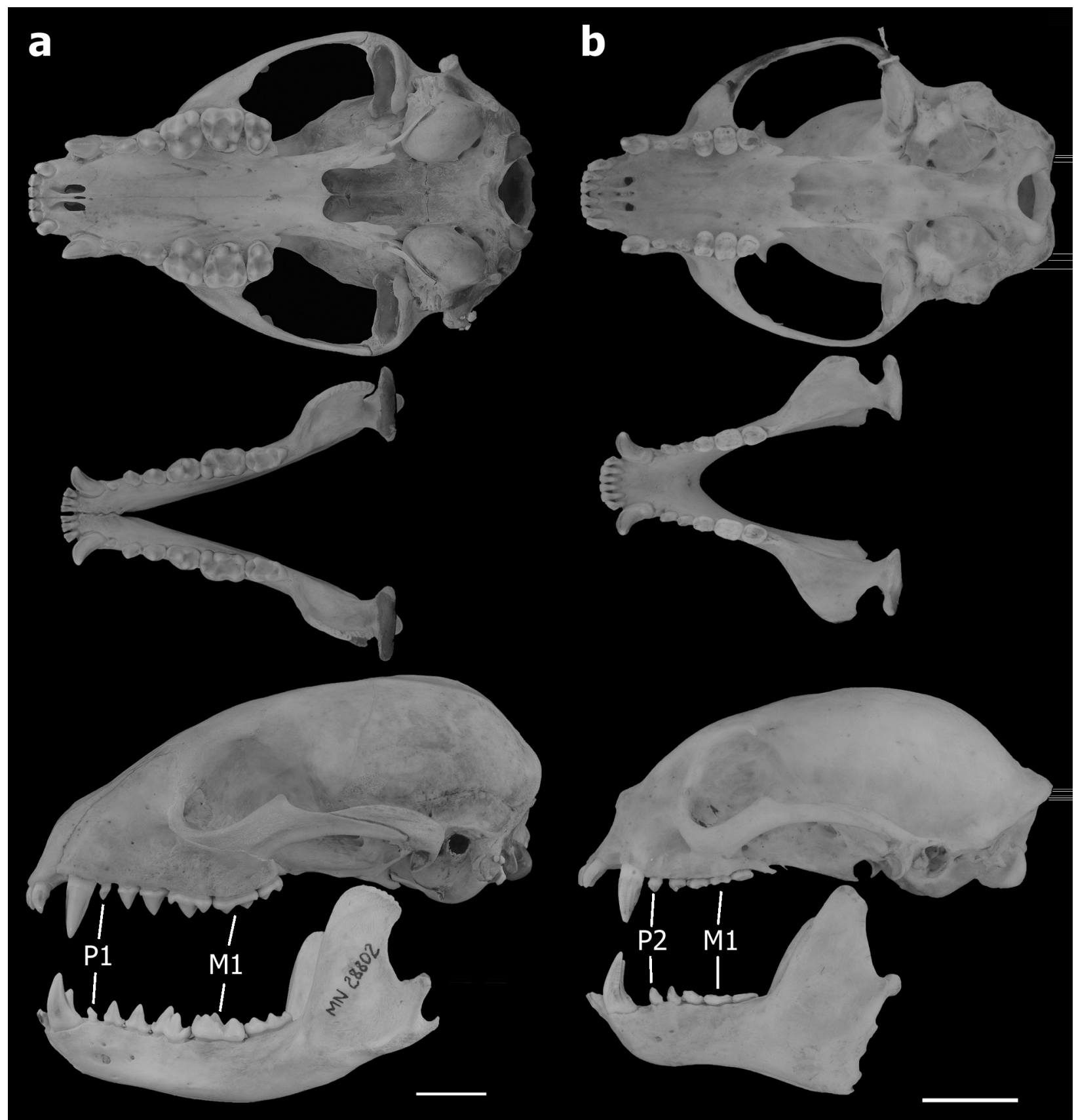

Figure 7. Occlusal (top) and lateral (bottom) views of the skull and mandible of: a) Procyon cancrivorus (MN28802); b) Potos flavus (MN68610). Abbreviation " $\mathrm{P}$ " means premolars and " $\mathrm{M}$ " molars. Scale bar $=2 \mathrm{~cm}$.

increase posteriorly in size, but only slightly. The first molar, the carnassial, is the largest lower tooth, with a trigonid as large as the talonid. The last molar is small without conspicuous cusps.

The only variation found among otters was a specimen (MN70163) of L. longicaudis with P
$3 / 2$, creating a diastema between these teeth and the canines.

The examination of two skulls of juvenile specimens of L. longicaudis (Fig. 5a; appendix 1) shows that the first upper postcanine teeth are not replaced, at least not at the same time as others. This tooth is followed by three 
postcanine teeth that are replaced. Therefore, these four teeth are all premolars, and are succeeded by one molar. In Lontra, the third and fourth deciduous upper premolars assume the form of carnassial and molar teeth, respectively.

Individuals of Eira barbara (Linnaeus 1758) and Galictis spp. have the dental formula I 3/3, $\mathrm{C} 1 / 1, \mathrm{P} 3 / 3, \mathrm{M} \mathrm{1/2}=34$ (Fig. 6a). This pattern is very similar to that of Pteronura and Lontra, with the exception that the former taxa do not have the first upper premolar. A tiny unpaired M2 was found in one individual (MN75066) of G. vittata (Schreber 1776). In three juvenile specimens of E. barbara examined (appendix 1), three upper deciduous premolar teeth are shed and replaced (Fig. 5b). The third and fourth decidual premolars in E. barbara depict carnassial and molariform shapes, respectively.

Individuals of Mustela africana Desmarest 1818 have I 3/3, C 1/1, P 2-3/2, M 1/2 = 30-32 (Fig. $6 \mathrm{~b})$. Of the four examined specimens, two had two upper premolars and the other half had three upper premolars. Again, the dental pattern is similar to previous Mustelidae taxa, although the loss of one or two upper premolars creates a diastema between the remaining premolars and the canine. Additionally, the loss of one lower premolar creates a diastema between the remaining premolars, and between premolars and canines. There were no juvenile specimens of M. africana available for examination.

\section{Procyonidae}

Two dental formulae are observed among members of this family, both with the same number of teeth on upper and lower jaws: I 3/3, C 1/1, P 4/4, M 2/2 = 40 (Fig. 7a), as seen in Bassarycion alleni Thomas 1880, Nasua nasua (Linnaeus 1766) and Procyon cancrivorus (G. Cuvier 1798); and I 3/3, C 1/1, P 3/3, M 2/2 = 36 (Fig. 7b), observed only in Potos flavus (Schreber 1774). As usual, premolars increase and molars decrease in size posteriorly. The last upper premolar does not depict the form of the typical carnassial tooth but, instead, is very similar in size and shape to the first molar. The first molariform tooth, thus, is the last premolar, which is preceded by three premolariform premolars and succeeded by two molars. The typical carnassial shape is also missing on the lower jaw.

The examination of 14 juvenile specimens of $N$. nasua (appendix 1) shows that the first postcanine tooth does not shed, while the three following postcanine teeth are replaced; this reinforces the premolar identity of these postcanine teeth on upper and lower jaws. The remaining two teeth are molars, which are not replaced. The examination of five juvenile specimens of $P$. flavus (appendix 1) shows that the first three postcanine teeth are replaced with permanent ones (i.e., are premolars), and the last two teeth are molars.

\section{DISCUSSION}

The data presented here contrast with the dental formulae proposed by some of the most important books about Neotropical mammalian fauna (e.g.: Eisenberg 1989, Emmons \& Feer 1997, Eisenberg \& Redford 1999, Labate et al. 2001, Cheida \& Santos 2010). All consulted books have one or more mistakes about carnivores' dental formula, as discussed below. Thus, we propose a concise identification key based on the correct formulae and teeth morphology of Brazilian carnivores (see appendix 2).

\section{Canidae}

Our study corroborated that individuals of all taxa of this family, except for S. venaticus, have two upper molars as previously observed by Eisenberg (1989), Emmons \& Feer (1997), 
Eisenberg \& Redford (1999), and Cheida \& Santos (2010). In contrast, Pessutti et al. (2001) wrongly proposed that Brazilian Canidae has three upper molars. The loss of the third upper molar is a synapomorphy of Carnivora (WesleyHunt \& Flynn 2005). Additionally, the loss of one additional molar on both upper and lower jaws in Speothos venaticus, resulting in $M 1 / 2$, was neglected by Pessutti et al. (2001).

Eisenberg (1989) and Eisenberg \& Redford (1999) suggested that specimens of S. venaticus have one or two upper molars, while SilleroZubiri (2009) proposes two upper molars for this species. There is a report of one S. venaticus specimen from Guyana that has two upper molars (Flower 1880). This author suggested that this could be the first examined specimens to have $\mathrm{M} \mathrm{2/2}$ and mentioned that the variation found could be a peculiarity of this specimen, or a tooth commonly lost in older adults. Those findings, coupled with our present results, indicate a polymorphism in this species. As only one specimen among five examined here has two upper molars, the basic dental formula of $S$. venaticus is considered as / 3/3 C 1/1 P 4/4 M 1/2. Additionally, Speothos pacivorus (Lund 1839), a fossil form, was redescribed by Berta (1984) with $P 4 / 4$ and $M 2 / 2$. This author mentions that $M 2$ is rarely present in $\mathrm{S}$. venaticus and that this is one important difference between the extant and extinct species. Without mentioning the dental formula, Paula-Couto (1953) suggested that the total tooth number in Speothos may vary between 36 and 40, but the evidence indicate a variation between 38 and 40 teeth.

Sillero-Zubiri (2009) reported that Cerdocyon thous has one upper and two lower molars and a total of 44 teeth, contrary to our observation of two upper and three lower molars and a total of 42 teeth. Although C. thous showed a slight variation in the dental formula, resulting in $40,42,43$ or 44 teeth, we did not find a single specimen with the formula mentioned by sillero-Zubiri (2009).

\section{Felidae}

Individuals of Neotropical Felidae genera have two or three upper premolars according to Eisenberg (1989), Emmons \& Feer (1997) and Eisenberg \& Redford (1999). The authors did not mention which species has one or another dental formula, and the few skull drawings in the Eisenberg (1989) and Eisenberg \& Redford (1999) show three upper premolars. Garcia-Perea (1994), however, found that among eight examined specimens of Leopardus braccatus (previously considered part of L. colocolo), only three had two premolars on the upper jaw. Of three $L$. braccatus examined here, only one (MN63629) has an unpaired second premolar on the right side, and no sign of this tooth or alveolus on the left side; the remaining two specimens (MN4868, MN24904) have only two premolars. L. tigrinus also has specimens (MN3133, MN49354, MN79565, MN84552) with just two pairs of premolars on upper jaw. Specimens of L. wiedii (Schinz 1821), Puma concolor (Linnaeus 1771), and Panthera onca consistently have three upper premolars.

Regardless of the variation in upper premolars, there are always two premolars on the lower jaw in all examined Felidae specimens, contradicting Cheida \& Santos (2010) proposal of P 3/3. The dental formula suggested by Cheida \& Santos (2010) seems to be a misrepresentation, since the total number of 30 teeth proposed by them fits the formula I 3/3, C 1/1, P 3/2, M 1/1 as suggested here, and not with the formula involving $P 3 / 3$.

\section{Mephitidae}

Exemplars of the two species of Conepatus have $P 2 / 3$ and $M 1 / 2$, but previous compendia included the taxon among the Mustelidae and wrongly provided its dental formula as the same 
for that family, P $3 / 3$ and M 1/2 (Eisenberg 1989, Emmons \& Feer 1997, Eisenberg \& Redford 1999, Pimentel et al. 2001); only Cheida \& Santos (2010) correctly proposed Conepatus dental formula. Nevertheless, one of the eight specimens examined here has three upper premolars. Van Gelder (1968), based on museum vouchers, reported the formula for Conepatus chinga from Uruguay as I 3/3, C 1/1, P 2/3, M 1/2. The author also reported that a few specimens (number not mentioned) among the 103 examined had three upper premolars, stating that this is not common and that the usual formula involved only two upper premolars.

\section{Mustelidae}

The general dental formula of Neotropical mustelids is $13 / 3, \mathrm{C} 1 / 1, \mathrm{P} 3 / 3, \mathrm{M} 1 / 2$, except for the Lutrinae taxa Lontra longicaudis and Pteronura brasiliensis, which is $P$ 4/3. Previous works have only reported the general formula for the family (Eisenberg 1989, Eisenberg \& Redford 1999, Pimentel et al. 2001), but Cheida \& Santos (2010) also reported the formula of Pteronura brasiliensis as found here.

Emmons \& Feer (1997) described variation on the family's postcanine dental formula as $P$ 3-4/3-4, M 1/1-2, but it is not possible to infer if the variation in the number of premolars and molars is intraspecific, interspecific, or even intergeneric. More importantly, although our sample is small for some of the examined taxa and does not include Mustela frenata Lichtenstein 1831, we did not find a single specimen with four lower premolar or with only one lower molar, as suggested by these authors. Even the inclusion of Conepatus within the Mustelidae, as followed by Emmons \& Feer (1997), would not explain the formula variation.

The dental formula of Mustela africana described here differs from the general family trend and agrees with that of Ramirez-Chaves et al. (2014), which reported the variation in premolar number $\mathrm{P} 2-3 / 2, \mathrm{M} 1 / 2$. These authors suggest that this dentition is specialized for a carnivorous diet, although nothing is known on this matter (Larivière \& Jennings 2009) or any other aspect of its biology (Oliveira 2009). Eira barbara has an omnivorous diet (see Presley 2000 for revision), while Galictis vittata is predominantly carnivorous (see revision in Yensen \& Tarifa 2003). These two mustelid taxa, with three premolars, have different diets and the same dental formula, a similarity that could be a result of phylogenetic constraint. Unfortunately, the lack of resolution for most carnivores' phylogenetic trees precludes a proper test of this hypothesis (Popowics 2003).

\section{Procyonidae}

There is an agreement about the constancy of the dental formula for most Brazilian Procyonidae (Eisenberg 1989, Emmons \& Feer 1997, Eisenberg \& Redford 1999, Labate et al. 2001, Cheida \& Santos 2010). The formula I 3/3, C 1/1, P 4/4, M $2 / 2=40$ is largely accepted for Procyonidae, although an exception is known for Potos flavus. Eisenberg (1989), Eisenberg \& Redford (1999) and Cheida \& Santos (2010) agree that P. flavus specimens have $P 3 / 4$ and $M 2 / 2$, while Emmons \& Feer (1997) and Labate et al. (2001) suggest $P$ $3 / 3$ and $M$ 2/2; the dental formula found here for $P$. flavus supports the latter authors. The difference in dental formula between P. flavus and other examined Procyonidae could be related to different diets: while Potos flavus is mainly frugivorous, the remaining Neotropical procyonids are mostly omnivorous (Kays 2009).

The family Procyonidae contains more omnivorous species when compared to the other examined families (Kays 2009). This is evident in the general form of the last premolar, which is molariform without the prominent blades of common carnassial (Hillson 2005). 
Consequently, this family has no clear morphological distinction between premolars and molars. On the other hand, the number of six postcanine teeth can be used to infer the identity of each tooth. As the total number of premolars in ancestral forms are four (Cifelli 2000), and members of the order Carnivora have lost the third upper molar (Wesley-Hunt \& Flynn 2005), the six postcanine teeth are necessarily four premolars and two molars on the upper jaw.

\section{CONCLUSIONS}

We found inconsistencies between our review and dental formulae described in several widely used books on Neotropical mammalogy. In turn, our resultsalso corroborate previous descriptions based on vouchered material. Our review shows that several incongruences were replicated in these books for the lack of examination of museum vouchers, propagating erroneous information without critical analysis. This calls the attention for misleading information about fundamental systematic characters of these flagship species and reinforces the importance of scientific collections as the primary source of phenotypic data.

\section{Acknowledgments}

We are grateful to Gisela Sobral, Marcos Cruz and Emily Bouza for the critical review of this manuscript and to João Alves de Oliveira, who allowed the access to the mammal collection of Museu Nacional/UFRJ. We also would like to thank Cibele R. Bonvicino for support of the project, and the thoughtful reviewers. This research was supported by grants from Coordenação de Aperfeiçoamento de Pessoal de Nivel Superior to FG [CAPES 88882.183261/2018-01] and the Conselho Nacional de Desenvolvimento Científico e Tecnológico, Brazil (CNPq) and Fundação de Amparo à Pesquisa do Estado do Rio de Janeiro (FAPERJ) to MW [CNPq 481286/2011-0, CNPq 440663/2015-6 and FAPERJ E-26/110.505/2012].

\section{REFERENCES}

BERGQVIST LP. 2003. The role of teeth in mammal history. Braz J Oral Sci 2: 249-257.

BERTA A. 1984. The Pleistocene bush dog Speothos pacivorus (Canidae) from the Lagoa Santa Caves, Brazil. J Mammal 65: 549-559.

CHEIDA CC \& SANTOS LB. 2010. Ordem Carnivora. In: Reis NR et al. (Eds). Mamíferos do Brasil, guia de identificação, Rio de Janeiro: Technical Books Editora, Rio de Janeiro, Brazil, p. 463-492.

CIFELLI RL. 2000. Counting premolars in early eutherian mammals. Acta Paleontol Pol 2: 195-198.

COPE ED. 1879. The origin of the specialized teeth of the Carnivora. Am Nat 13: 171-173.

EISENBERG JF. 1989. Mammals of the Neotropics. The northern Neotropics: Panama, Colombia, Venezuela, Guyana, Suriname, French Guiana. Chicago: University of Chicago Press, $449 \mathrm{p}$.

EISENBERG JF \& REDFORD KH. 1999. Mammals of the Neotropics. The central Neotropics: Ecuador, Peru, Bolivia, Brazil. Chicago: University of Chicago Press, 609 p.

EMMONS LH \& FEER F. 1997. Neotropical rainforest mammals: a field guide. Chicago: University of Chicago Press, $307 \mathrm{p}$.

FLOWER WH. 1880. On the Bush-dog (Icticyon venaticus, Lund). P Zool Soc Lond: 1-9.

GARCIA-PEREA R. 1994. The pampas cat group (genus Lynchailurus Severtzov, 1858) (Carnivora: Felidae), a systematic and biogeographic review. Am Mus Novit 3096: 1-36.

HILLSON S. 2005. Teeth. Cambridge: Cambridge University Press, $373 \mathrm{p}$.

KAYS R. 2009. Family Procyonidae (Raccoons). In: Wilson D et al. (Eds). Handbook of the Mammals of the World. Vol. 1. Carnivores, Barcelona: Lynx Edicions, $727 \mathrm{p}$.

LABATE AS, NUNES ALV \& GOMES AS. 2001. Order Carnivora, Family Procyonidae (Raccoons, Kinkajous). In: Fowler ME and Cubas ZS (Eds). Biology, Medicine and Surgery of South America Wild Animals. Ames: Iowa State University Press, $536 \mathrm{p}$.

LARIVIĖRE S \& JENNINGS AP. 2009. Family Mustelidae (Weasels and relatives). In: Wilson D et al. (Eds). Handbook of the Mammals of the World. Vol. 1. Carnivores, Barcelona: Lynx Edicions, 727 p.

LUCKETT WP. 1993. An ontogenetic assessment of dental homologies in therian mammals. Mammal phylogeny. In: Szalay FS et al. (Eds). Mammal Phylogeny: Mesozoic differentiation, Multituberculates, Monotremes, early 
Therians, and Marsupials. New York: Springer-Verlag, 260 p.

NOVACEK MJ. 1986. The primitive eutherian dental formula. J Vertebr Paleontol 6: 191-196.

OLIVEIRA TG. 2009. Notes on the distribution, status, and research priorities of little-known small carnivores in Brazil. Small Carniv Conserv 41: 22-24

OWEN R. 1840-45. Odontography, vol. I. London: Hippolyte Bailliere, $655 \mathrm{p}$.

PAGLIA AP ET AL. 2012. Lista anotada dos mamíferos do Brasil / Annotated checklist of Brazilian mammals. 2a Edição / 2nd Edition. Occasional Papers in Conservation Biology, No. 6. Arlington: Conservation International, 76 p.

PAULA-COUTO C. 1950. Memórias sobre a Paleontologia Brasileira. Rio de Janeiro: Instituto Nacional do Livro, $591 \mathrm{p}$.

PAULA-COUTO C. 1953. Paleontologia Brasileira. Mamíferos. Rio de Janeiro: Instituto Nacional do Livro, 516 p.

PAULA-COUTO C. 1979. Tratado de Paleomastozoologia. Rio de Janeiro: Academia Brasileira de Ciências, 590 p.

PESSUTTI C, SANTIAGO MEB \& OLIVEIRA LTF. 2001. Order Carnivora, Family Canidae (Dogs, Fox, Maned Wolves). In: Fowler ME and Cubas ZS (Eds). Biology, Medicine and Surgery of South America Wild Animals. Ames: Iowa State University Press, 536 p.

PIMENTEL TL, REIS ML \& PASSERINO AS. 2001. Order Carnivora, family Mustelidae. Biology, Medicine and Surgery of South America Wild Animals. In: Fowler ME \& Cubas ZS (Eds). Biology, Medicine and Surgery of South America Wild Animals. Ames: Iowa State University Press, 536 p.

POPOWICS TE. 2003. Postcanine dental form in the Mustelidae and Viverridae (Carnivora: Mammalia). J Morphol 256: 322-341.

PRESLEY SJ. 2000. Eira barbara. Mamm Species 636: 1-6.

RAMíREZ-CHAVES HE, ARANGO-GUERRA HL \& PATTERSON BD. 2014. Mustela africana (Carnivora: Mustelidae). Mamm Species 46: 110-115.

REIS NR, PERACCHI AL, FREGONEZI MN \& ROSSANEIS BK. 2010. Mamíferos do Brasil, guia de identificação, $1^{a}$ Ed. Rio de Janeiro: Technical Books Editora, 557 p.

SAVAGE RJG. 1976. Evolution in carnivorous mammals. Palaeontology 20: 237-271.

SILLERO-ZUBIRI C. 2009. Family Canidae. In: Wilson D et al. (Eds). Handbook of the Mammals of the World. Vol. 1. Carnivores, Barcelona: Lynx Edicions, 727 p.

UNGAR PS. 2010. Mammal teeth: origin, evolution and diversity. Baltimore: John Hopkins University Press, 304 p.
VAN GELDER RG. 1968. The genus Conepatus (Mammalia, Mustelidae): variation within a population. Am Mus Novit 2322: 1-37.

VAN VALKENBURGH B. 1991. Iterative evolution of hypercarnivory in canids (Mammalia: Carnivora): evolutionary interaction among sympatric predators. Paleobiology 17: 340-362.

WESLEY-HUNT GD \& FLYNN JJ.2005. Phylogeny of the Carnivora: basal relationships among the carnivoramorphans, and assessment of the position of 'miacoidea' relative to carnivore. J Syst Palaeontol 3: 1-28.

WINGE H. 1895. Jordfundne og nulevende rovdyr (Carnivora) fra Lagoa Santa, Minas Geraes, Brasilien: med udsigt over pungdyrenes slægtskab. Kjøbenhavn: F. Dreyer, $134 \mathrm{p}$.

YENSEN E \& TARIFA T. 2003. Galictis vittata. Mamm Species 727: $1-8$.

\section{APPENDIX 1}

List of examined specimens; all specimens are composed by skull and mandible and are housed at Museu Nacional/UFRJ (MN/UFRJ). Marked (*) individuals indicate juvenile specimens, i.e., with a deciduous tooth; those not marked are all adult individuals, i.e., those with full permanent dentition.

\section{Canidae}

Atelocynus microtis: MN650.

Cerdocyon thous: MN-JFV321, MN-JFV334, MN-P1, MN-PRG1370, MN670*, 932, 1364, 1389*, 3036, 3038, 3885, 3887, 4242-4243, 4891, 4908, 5496, 5505, 5881, 7576, 8469, 8479, 10986-10987, 10993, 11205, 11397*, 25005, 25551-25554, 25556, 25559-25560*, 25570, 25577-25579, 25580*, 25581*, 25582-25584, 25585*, 25586*, 25587, 25589-25594, 25597-25603, 25605-25608, 25612, 25683, 25688, 26775, 29061-29062, 30584, 30586, 32370-32371, $36759,37658,41227,42800,43968,46810,46853$, 47670, 55054, 59010, 61838, 63471, 63491, 63505, 63517, 64258, 64573, 64685, 67574, 68181, 68361, $68367,68370^{*}, 68385,70835,70858,71067^{\star}, 71084$, 71092, 71155, 72784, 73473, 75036, 75086, 75090, 75092, 75981, 79026, 79109-79110, 79168, 79172, 79193, 79196, 79225, 79243, 79252, 79288, 79292, 
79359, 79377, 79393, 79398-79399, 79408, 79410, 79414, 79418, 79460, 79464, 79475, 79483, 79485, 79486, 79509, 79515, 79547, 79563, 79578, 79593, $81068,81779 *, 81788,81791,83590,83601-83602$, 83630-83631.

Chrysocyon brachyurus: MN640, 664, 1049, $3041^{*}, 3049^{*}, 3055,4815,4899^{*}, 17501-17502,32372$, 36666, 62552, 68175, 69817, 70999, 71086, 79031*, 79113, 79117, 79195, 79386, 79396, 79411, 79481.

Lycalopex vetulus: MN651, 655-656, 3037, 3039-3040, 3044, 4241, 4909, 5151, 32428, 68180, 71039, 71045, 71047, 71093, 71112, 71160, 71173, 72779*.

Lycalopex gymnocercus: MN2355.

Lycalopex sp.: MN652.

Speothos venaticus: MN3033, 3035, 25668, 25670, 75089.

\section{Felidae}

Leopardus braccatus: MN4868, 24904, 63629. Leopardus pardalis: MN620-622, 624-625, 3156, 4811, 4817, 5679, 7630, 24875-24876, 2488024884, 25691, 25693, 48873-48878, 48880, 68156, 71609, 79122, 79273, 79291, 79557, 79558, 83607, $84555,84557$.

Leopardus tigrinus: MN610, 1363, 1690, 3133, 5145, 5885, 6693, 7261, 24894-24896, 25650-25651, 25653, 25726, 49354, 49356, 71153, 74386, 79051, 79465, 79480, 79565, 79583, 84550, 84552-84554.

Leopardus wiedii: MN1382*, 5114*, 5621, 6066*, 18813, 24886-24887, 24890*, 24910*, 25723, 72785, 79530.

Panthera onca: MN-TX69, MN633-634, 1007, 1013, 1015, 1017, 1021, 1022*, 1023, 3349, 13508, 24858*, 24860-24863, 32375*, 32376*, 32705, 32707, 36218, 48868, 48869, 71161, 77863.

Puma concolor: MN381, 985, 1014, 1016, 10181020, 1025, 1029, 3351, 6022-6023, 17506, 24865, 24867, 24869, 24872*, 49074-49075, 53862, 71077, 71085.

Puma yagouaroundi: MN384, 1039, 1043, 1381, 3140-3141, 3153, 4893, 24885, 24901-24902, 49076, 49316, 75985, 79049, 79158, 79280, 79329, 79490, 79548.

\section{Mephitidae}

Conepatus chinga: MN3128.

Conepatus semistriatus: MN1500, 13385, 29990, 30000, 59335, 63316.

\section{Mustelidae}

Eira barbara: MN669, 3100, 3102, 3106-3107, 4904, 4906-4907, 5163*, 5512, 5619*, 5649, 5791, 5959-5960, 6085, 6088-6089, 7611, 10990, 25686, 29976, 29977, 30003, 51650, 63452, 68357-68358, 68365, 68625, 74385*, 75096, 79526.

Galictis cuja: MN677, 687, 1160, 1498-1499, 1506, 1755, 1882, 3127, 3129, 3131, 4845, 5809, 7258, $7322,8236-8238,10508,11181-11183,25684,29980-$ 29988, 29998-29999, 30001, 42018, 43947, 69904, 79190, 79216, 79314, 79379, 79510.

Galictis vittata: MN3093, 3115, 29989, 29993, 75066 .

Lontra longicaudis: MN684*, 3020, 3023, 3031, 22255, 25680, 25682, 30002, 50799-50800*, 69898, 70163, 79200, 81789.

Mustela africana: MN3121-3122, 29979, 66495.

Pteronura brasiliensis: MN3024, 32700, 42695, 50801, 50802*, 50803, 73635, 77231.

\section{Procyonidae}

Bassaricyon alleni: MN69145, 69149-69150.

Nasua nasua: MN-MOL30, MN358-361, 363365, 367, 999, 1418, 3050, 3062, 3064-3065, 3068, 3073, 3075-3076, 3081-3084, 3096, 3099, 3841-3844, 4048, 4074, 4717, 4861, 4879, 4883-4888, 4892, 4901, 4905, 4911-4912, 5205*, 5506, 5622, 5628, 5633, $5709,5723,5727^{*}, 5810,5872 *, 5925-5926,5942$, $6033^{*}, 6034,6067,6087,6695,6697,7263,7311$, 7626-7627, 7658*, 8482, 8504, 11605, 23876-23883, 24783*, 24786-24788*, 24798-24799*, 24801, 24804$24809,24812-24813,24814^{*}, 24815-24818,24822$, 24824, 24826, 25679*, 25699, 28502*, 32388-32389, $32392-32393,32395-32396,32398,32431,32436^{*}$, 37630, 64002, 64006, 64068, 65558, 66177-66180, 71046, 71064, 71071, 71157, 71159, 72361*, 73169*, 75084, 79047, 79123, 79293, 79349, 79392, 79549.

Potos flavus: MN-M18096, MN1078, 3089, 3098, 4851, 4862*, 4866, 4867*, 4874, 4876-4877, 
4880*, 4881, 4902-4903, 5162, 5617, 5639, 5689, 5714, 5716, 5721-5722, 5774, 10965-10972, 10992, $11396,24925,32391^{*}, 32406-32423,55500,68610$, 69118, 69129, 69298*.

Procyon cancrivorus: MN1044, 1497*, 3087, 3094, 4896-4897, 5503-5504, 5643, 7256, 7577, 7612,
7625, 11203, 23884-23887, 25310, 25657, 25689, 28802, 32374, 32377-32378, 32380-32382, 32384, 41102, 64438, 65559, 71087, 71090, 75093, 79170, 79344, 79540, 79568, 81067, 83591-83593.

\section{APPENDIX 2}

Identification key for Brazilian terrestrial Carnivora taxa based on dental

formulae and morphology:

1. $\mathrm{m} 2$ present . .2

1'. m2 absent Felidae

2.m3 present Canidae (except S. venaticus)

2'. m3 absent . .3

3.p1 present. . .4

3'. p1 absent. 5

4.P4 carnassial. Speothos venaticus 4'. P4 molariform Procyonidae (except $P$. flavus)

5.M2 present Potos flavus

5'. M2 absent 6

6.P4 present Lutrinae (Pteronura and Lontra)

6'. P4 absent .7

7.p3 present. . .8

7'. p3 absent. Mustela

8.Mesiodistally increasing upper postcanine series Mephitidae

8'. Mesiodistally increasing upper premolars and decreasing upper molars.... Eira and Galictis 


\section{How to cite}

GUDINHO FS \& WEKSLER M. 2021. On the Dental Formulae of Brazilian Terrestrial Carnivora (Mammalia). An Acad Bras Cienc 93: e20191384. DOI 10.1590/0001-3765202120191384.

Manuscript received on November 11, 2019;

accepted for publication on October 21, 2020

\section{FILIPE S. GUDINHO}

https://orcid.org/0000-0002-2510-0337

\section{MARCELO WEKSLER}

https://orcid.org/0000-0001-8111-4779

Universidade Federal do Rio de Janeiro, Departamento de Vertebrados, Museu Nacional, Setor de Mastozoologia, Quinta da Boa Vista, São Cristóvão, 20940-040 Rio de Janeiro, RJ, Brazil

Correspondence to: Filipe Souza Gudinho

E-mail:fsgudinho@gmail.com

\section{Author contributions}

FG conceived the idea, examined the specimens, took the pictures and wrote the manuscript and MW conceived the idea, reviewed data, and wrote the manuscript.

\section{(cc) BY}

